treatments and have benefited greatly by psychotherapy. That, of course, is not to say that all psychiatric patients should automatically receive psychotherapy; it may well be that psychotherapy is suitable for some people as a treatment method, or it may be that psychotherapy is suitable for certain psychiatric conditions or stages in their evolution or devolution. Nevertheless, unless research continues and evidence continues to be collected either for or against the argument in a scientific way we shall never know the answer. My colleagues and I in Plymouth are preparing a paper concerning our experiences in our psychotherapy clinic, which I hope will be ready for submission soon.

I feel that the tradition in British medicine of allowing treatments to evolve and to see the outcome in clinical practice has always stood the test of time. The theories later produced may or may not be accurate. We should be swayed by the evidence of effectiveness in the clinical setting rather than by opinions, no matter how carefully thought out, from our own heads. I cannot believe that colleagues in the general hospital and in general practice would continue to refer patients for psychotherapy were they to feel that patients did not benefit, nor do I believe that our patients are so stupid as to continue with a form of therapy which requires a high degree of concentration, hard work, and dedication if they did not derive some benefit from it.

From the practical point of view, until we have a Coulter counter, computed tomographic scanner, or multiple analyser to investigate feelings and emotions it seems likely that we shall have to keep listening to our patients. Psychiatrists will fail as we all do in medicine at times; some psychiatrists will let down their colleagues and patients. Some of those psychiatrists will practice psychotherapy. We are all prey to human failings but that is a different argument from that concerning the scientific or artistic merit of the methods we are trying to use. Perhaps we can learn the answers by studying our patients rather than the agenda of the next committee meeting? If the medical profession has lost respect and influence in the field of human behaviour we are unlikely to regain it by futile demarcation disputes with colleagues, but we may regain it through demonstrating our worth to our patients.

I suggest that more and not less investigation of the psychotherapeutic contribution is indicated and we should not be put off because that is a greater challenge than physical observation and experimentation.

W C Hughes

Moorhaven Hospital,
Ivybridge, S Devon PL21 oEX

SIR,-I have just read Professor M Shepherd's paper "Psychoanalysis, psychotherapy, and health services" (15 December, $p$ 1557). In the penultimate paragraph he refers to family therapy as "less specialised" than psychotherapy. This is not so. It is, however, an alternative, particularly when children or adolescents are involved. ${ }^{1}$ Evidence for its efficacy is probably stronger than that for individual therapy ${ }^{2}$ and there is great scope for it in child psychiatry and social work. I think that the experience and role of the health visitor is also an excellent basis from which to develop family therapy skills but, as with psychiatrists and social workers, advanced training is essential if effective help is to be given. Just interviewing families is not family therapy.

Sebastian Kraemer

Department for Children and Parents,

Tavistock Clinic ${ }^{1}$ Bruggen P, Davies G. Brit $\mathcal{F}$ Psychiat $1977 ; 131: 433$
2 Well R, Dezen A. Family Process $1978 ; 17: 251$.

\section{Services for the mentally handicapped}

SIR,-Dr Neil Gordon questions the need for consultants in mental handicap ( 9 February, p 403). He rightly comments that many of the problems of these patients are social and educational and that increasing contribution are being made to their care from these other services. However, despite this my experience over the past 10 years has been that there is an increasing demand for my contribution as a consultant psychiatrist (mental handicap) for help with diagnosis, assessment, treatment, and prevention.

An analysis of a sample of 233 cases seen in outpatients showed an age range of 1 month to 70 years, 113 being 16 or under. One hundred and twenty-five were male. More than half the cases (120) were referred from medical sources-general practitioners and school medical officers, and 44 from consultants (20 from paediatricians, 18 from psychiatrists, three from neurologists, two from physicians, and one from an orthopaedic surgeon). Social workers referred 111 cases.

By far the commonest reason for referral (134 cases) was behavioural abnormality: aggression in 23 ; sexual misbehaviour in 18; psychiatric symptoms in 27 ; tantrums and screaming in 18 disturbances of eating, sleeping, bowel, and bladde control in 29. Hyperactivity, destructiveness, wandering, and obstinancy also occurred frequently. Most had more than one abnormal behaviour an commonly another major problem; for example, of the 23 aggressive patients, 11 suffered from epilepsy. Court reports were written on 14 patients (eight cases of sexual offences, six of theft). Other reasons for referral included delayed development epilepsy; genetic counselling, and help in the elucidation of causes of physical symptoms. Help was sought in deciding the most suitable placement for occupation or residence in 65 cases. Seventy-six patients were admitted to an assessment unit ${ }^{1}$ for diagnosis and treatment. Eighteen of the children were admitted to long-term hospital care (six had been referred by paediatricians). Some of these have died or been discharged but 20 of the total group remain in long-term hospital care.

Most consultants in mental handicap would recognise this as similar to their own work load-and very dissimilar to that of a paediatrician or a child psychiatrist, although there are areas of overlap. It is also important to have access to special facilities. The residential assessment unit to which the patients were admitted is in a hospital for the mentally handicapped and has a multidisciplinary staff team. As well as my work in this unit I have under my care 400 long-stay hospital residents, many of whom require continual consultan psychiatric clinical care. ${ }^{2}$ My work includes teaching medical postgraduates, nurses, social workers, and others; there are case conferences and staff meetings as well as the administrative duties, which include hospital and divisional meetings. I visit community establishments and am involved in forward planning.

My work in a child guidance clinic and close contact with child psychiatric colleagues suggests that the pattern of working does not cater adequately for the needs of many mentally handicapped and their families. Often the only source of help is through the school. There are many child psychiatrists who have little interest in the organic deficits of their patients and there is as yet little evidence that they are widening their work load to include the mentally handicapped or that this will happen in the future. The biological, physiopathological, and psychiatric abnormalities in many of these patients require very special skills from their doctors. ${ }^{2}$ Their medical care must be a collaborative exercise but we should widen the training of both psychiatrists and paediatricians to include more experience with them.

Our local rotating psychiatric registrars spend six months based at a long-stay hospital with a programme which includes regular weekly attendances at a paediatric assessment centre, outpatients, and visits to community facilities. Paediatricians in training might also devote some of their time to gaining experience in the medical care of the children who are in mental handicap hospitals as they are a particularly severely handicapped group.

I hope that the creation of the first chair in mental handicap at St George's Hospital, London, will provide further stimulus to psychiatrists and other specialists in this field, and to future developments.

Stoke Park Hospital

R M WALTERS

\section{Wiley Y. Apex 1975;3:22-3, 26-7.}

James FE, Snaith RP, eds. Psychiatric illness and mental handicap. London: Gaskell Press, 1979.

SIR,-In general I agree with the views of Dr Neil Gordon (9 February, p 403) on services for the mentally handicapped. Those of us who have worked in mental handicap hospitals for a long time will realise from time to time how ineffective the service has become. This is mainly because of: (a) the absence of a clearcut definition of "mental handicap" and the aims of the service; $(b)$ not knowing who should have the ultimate responsibility for this group of people-hospitals or social services; $(c)$ the fact that the defects these people are suffering will last all their lives, so it has to be decided whether they are to benefit from a hospital service with drugs, etc, or by gradually improving their learning abilities with special education and social training in a residential school setting. One has to realise that "mental handicap" is not a disease; it is not even a syndrome-it is only a clinical "state of mind." Until we find some curative treatment for this state we can only try to ameliorate the severity of the symptoms and render them tolerable to the patient and society at large.

The present system of psychiatric treatment in National Health Service hospitals functions in a dichotomy of (a) mental illness and (b) mental handicap, but both are medically manned by psychiatrists and very often there is very little or no discourse between these two groups of medical people. The fact is that anyone with mental handicap is very likely to suffer emotional and behavioural disorders, and therefore an integrated service practising "comprehensive psychiatry" is essential for a service to be productive. I do not think paediatricians are of much help once the child has developed some emotional and behavioural disorder, and psychiatrists must equip themselves to cope with such cases. Too many cooks spoil the broth and so one, and only one, psychiatrist should deal with a 
case with the help of psychologists, neurologists, teachers, etc.

In order to provide an early effective service, the job of "looking after" a mentally handicapped child or adult must be removed from the auspices of the National Health Service and entrusted to each county special education department, which will run special schools with residential places for these children. Mentally handicapped adults require residential hostels along with "sheltered workshops" where they can earn a fair wage commensurate with their productive capacity. Thinking and behavioural disorders developing in these two groups of people should then be treated by a psychiatrist as with any other group. If such a patient cannot return to his residential hostel, then he or she will be taken into a psychiatric hospital for long-term or short-term treatment according to the medical necessity. His or her return to the original residential setting should remain a distinct possibility at all times.

I think the time has come to reconsider and reform the mental handicap service in this country to make it more productive (both in the clinical and in the monetary sense) and to minimise waste.

U J DEY

Brockhall Hospital,

\section{Royal organs}

SIR,-YYour leading article "Renal transplantation in the 1980s" (23 February, p 503) points to the continuing difficulties in obtaining a satisfactory supply of cadaveric kidneys and the same presumably applies to other useful donor organs. I put forward a suggestion which, had it been taken up, might have improved matters. ${ }^{1}$

During the past few centuries the British Royal Family have at times exercised a considerable influence on medical practice. Even if we leave aside such interesting antiquities as the royal touch, Queen Victoria made anaesthesia in childbirth respectable literally overnight, while Edward VII may have had a rather similar effect on the diagnosis of appendicitis.

If any member of the Royal Family were to carry a donor card and publicise the fact, might not this increase the willingness of the public to donate and of doctors to ask the right questions at the right time? Old taboos seem to disappear more quickly when they are broken by leaders of a society. There is also the point that if, through the Royal Warrant, the Royal Family endorse the products of tobacco companies, surely they can spare a little support for procedures which may sometimes be useful in treating tobacco-induced diseases.

Colin BRewer

London NW8

${ }^{1}$ Brewer C. Gen Pract 17 March 1978:31.

\section{New scheme for organ donors}

SIR,-You will know that the Medic Alert Foundation has recently launched a new scheme to enable members of the public who wish to be organ donors to wear a bracelet or necklet indicating this. We were interested to read your leading article (16 February, p 427) on the whole transplant problem, but felt that a mention might have been made of the Medic Alert system as we believe that this, if widely supported, would greatly increase the harvest of organs for transplantation.

\section{David Caro} Secretary to Advisory Council,
Medic Alert Foundation

Accident and Emergency Department,

St Bartholomew's Hospital,
London EC1A 7BE

\section{Volkmann's ischaemic contracture}

SIR,-I would like to draw attention to one point which was made in your recent excellent leading article on Volkmann's ischaemic contracture (16 February, p 430). Although it is certainly important to examine for nerve function in the early stages for diagnosis, it is irreversible damage to muscle, not nerve, which is the most important feature of ischaemia of any limb. Seddon ${ }^{1}$ noted that the vulnerability of nerve is considerably less than that of muscle. It is the function of nerves that is rapidly affected by ischaemia, as was shown by Lewis et al in 1931.2 Lundborg $^{3}$ has clearly shown that the intraneural microcirculation recovers completely after six to eight hours of circulatory arrest. Muscle fibres show changes after as short a time as one hour, ${ }^{4}$ and after six to eight hours irreversible changes will occur. ${ }^{5}$

Northwick Park Hospital and Clinical

Research Centre

Harrow, Middx HA1 3UJ

1 Seddon H. Br Med f 1964 ; i :1587-92.

2 Lungborg G. Scand $\mathcal{f}$ Plast Reconstr Surg 1970;

suppl 6. Pickering G, Rothschild P. Heart 1931-3; 16:1-31.

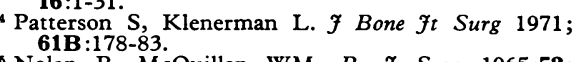

Nolan B, MCQuillan WM. Br f Surg 1965;52:

Sharp A. Med f Aust $1964 ; 51: 210-4$.

\section{Antibiotic treatment for gangrenous and} perforated appendix

SIR,-Mr D J Pinto and Dr P J Sanderson (2 February, $p$ 275) make recommendations for prevention of wound infection in patients with gangrenous appendix that are irrational and the recommendations for prevention of wound infection in patients with perforated appendix are inadequate.

Treatment with metronidazole for five days reduced wound infection in patients with gangrenous appendix to $4.5 \%$. This rate is marginally lower than the wound infection rate in their patients with normal or inflamed appendix, whether untreated controls or treated with metronidazole perioperatively, in whom the wound infection rates were $7 \cdot 7 \%$ and $5 \cdot 2 \%$ respectively. As they accept these latter wound infection rates and advise no antibiotics for such patients, it is surely irrational, despite the title of their paper, to recommend additional antibiotics for the regimen in gangrenous appendix, in which a lower wound infection rate had been demonstrated.

In perforated appendix wound infection rates commonly exceed $50 \%$ and their recommendation of full-spectrum systemic antibiotics for five days is essential. However, it is surprising that the advantages of intraoperative antibiotic peritoneal and wound lavage ${ }^{12}$ have been overlooked again, ${ }^{34}$ and until this technique is widely applied I foresee little reduction in the alarmingly high rate of wound infection in patients with perforated appendix.

Royal Infirmary,
Edinburgh EH3 9Yw

Douglas Stewart

${ }^{1}$ Noon GP, Beall AC, Jordan GL, Riggs S, De Bakey ME. Surgery 1967;62:73-8.
2 Stewart DJ, Matheson NA. Br $\mathcal{F}$ Surg 1978;65:54-6,

Anonymous. Br Med F 1979;ii 691.

Stewart DJ. Br Med fै 1979;ii:1364-5.

\section{Antibiotics in appendicectomy}

SIR,-The conclusions reached by Mr D J Pinto and Mr P J Sanderson in their interesting paper (2 February, p 275) bear further scrutiny and analysis. In keeping with the practice adopted in several recent studies, ${ }^{1-3}$ metronidazole was given as a suppository one hour before surgery, so that peak blood levels would be reached at the time of contamination of the wound. Ampicillin, however, was given intramuscularly preoperatively after the appendix had been brought to the surface, and therefore after it would have impregnated the wound with bacteria in its passage to the exterior. Not only was ampicillin a non-starter on this count but it was also stuck with the unfair disadvantage of having to cope with twice as many perforated appendices ( 16 as against eight for metronidazole).

Having, however, analysed their data from this protocol the authors go on to recommend that if a gangrenous or perforated appendix is encountered metronidazole should be given intravenously during the operation, together with cephazolin, a chemotherapeutic regimen which bears no relation to that given to their patients.

Other forms of therapy ${ }^{4}$ compare favourably with the wound infection rate of $16 \%$ in patients with perforated appendicitis receiving metronidazole in this trial and clearly an improvement on this figure must be shown in a controlled study before a new antibiotic regimen is recommended. John Radcliffe Hospital,
Oxford OX3 9DU

A KINGSNORTH

${ }^{1}$ Willis AT, Ferguson IR, Jones PH, et al. Br Med $\mathcal{F}$ 1976;i:318.

Rodgers JD, Ross P, McNaught W, Gillespie G. $\mathrm{Br}$ F Surg $1979 ; 66: 425-7$

${ }^{3}$ Salem RJ, Johnson J, Devitt P. Br $\mathcal{F}$ Surg 1979;66: 430-1.

Pollock AV, Evans M. Br f Surg 1977;64:322-5. Pollock AV, Froome K, Evans M. Br f Surg 1978;65:

SIR,-As a cost-conscious surgical senior registrar I spend my time trying to coax SHOs into doing fewer out-of-hours tests and using cheap drugs. Consequently I was concerned to find no reference to cost in the consultant surgicopathological advice from Northwick Park Hospital on antibiotic therapy in gangrenous appendicitis (2 February, $p$ 275). Mr D J Pinto and Dr P J Sanderson recommend metronidazole $500 \mathrm{mg}$ intravenously + cephazolin $1 \mathrm{~g}$ intramuscularly every eight hours for five days, but also say that metronidazole may be given by suppository.

A telephone call to our pharmacy confirms the following prices for metronidazole: one bottle $500 \mathrm{mg}$ (intravenous)- $£ 6.40$; one suppository $500 \mathrm{mg}$ (per rectum)-33p; two 200-mg tablets (oral)-15p. There is a twentyfold difference between the first two.

Although a single peroperative intravenous dose of metronidazole may be countenanced, 